\title{
Empréstimo bancário: uma proposta de ensino à luz da Pesquisa Baseada em Design
}

\author{
Bank loan: a proposal for teaching in the light of Design-based \\ Research
}

Préstamo bancario: una propuesta para la enseñanza a la luz de la Investigación Basada en el Design

Denise Ritter ${ }^{1}$; Josiele Maria Fusiger ${ }^{2}$; Patricia Cristiane da Cunha Xavier ${ }^{3}$; Aline Grohe Schirmer Pigatto ${ }^{4}$; Eleni Bisognin ${ }^{5}$

\begin{abstract}
RESUMO
O estudo utiliza a abordagem da Pesquisa Baseada em Design (PBD) e tem por objetivo investigar as potencialidades de uma sequência de atividades que explora o Regime de Capitalização Composta para Empréstimos. Foi aplicada na disciplina de Matemática Financeira com estudantes do curso de Bacharelado em Administração. $O$ trabalho foi estruturado de acordo com as fases da PBD propostas por Reeves (2000), quais sejam: análise do problema educativo; elaboração do artefato pedagógico; intervenção; e, avaliação e reflexão para um redesign do processo. Na primeira fase foi realizada a análise do Projeto Pedagógico do curso de Administração, das Diretrizes da lei 9.394/96 e também dos trabalhos que tratam do ensino de Matemática Financeira; na segunda fase ocorreu a elaboração do artefato pedagógico; na terceira fase, a sequência foi aplicada e na quarta fase foram analisados o artefato e a proposta como um todo vislumbrando o redesign. Pode-se observar que as atividades propostas contribuíram para reflexão dos estudantes sobre a Educação Financeira a partir das aplicações do conteúdo em situações reais da vida cotidiana.
\end{abstract}

Palavras-chave: Empréstimo bancário; Educação Financeira; Sequência de atividades; PBD.

\section{ABSTRACT}

The study uses the Design-Based Research (PBD) approach and aims to investigate the potential of a sequence of activities that exploits the Compound Capitalization Scheme for Loans. It was applied in the discipline of Financial Mathematics with students from the Bachelor of Business Administration course. The work was structured according to the phases of the PBD proposed by Reeves (2000), namely: analysis of the educational problem; elaboration of the pedagogical artifact; intervention; and, evaluation and reflection for a redesign of the process. In the first phase, the Pedagogical Project of the Administration course, the Law 9.394 / 96 Guidelines and also the works that deal with the teaching of Financial Mathematics were analyzed; in the second phase, the pedagogical artifact was elaborated; in the third phase, the sequence was applied and in the fourth

${ }^{1}$ Doutoranda no Programa de Pós-graduação em Ensino de Ciências e Matemática da Universidade Franciscana (UFN), Santa Maria, RS - Brasil. E-mail: deniseritter10@gmail.com

2 Doutoranda no Programa de Pós-graduação em Ensino de Ciências e Matemática da Universidade Franciscana (UFN), Santa Maria, RS - Brasil. E-mail: mariajfusiger@gmail.com

${ }^{3}$ Doutoranda no Programa de Pós-graduação em Ensino de Ciências e Matemática da Universidade Franciscana (UFN), Santa Maria, RS - Brasil. E-mail: patcx@hotmail.com

${ }^{4}$ Professora no Programa de Pós-graduação em Ensino de Ciências e Matemática da Universidade Franciscana (UFN), Santa Maria, RS - Brasil. E-mail: agspigatto@gmail.com

${ }^{5}$ Professora no Programa de Pós-graduação em Ensino de Ciências e Matemática da Universidade Franciscana (UFN), Santa Maria, RS - Brasil. E-mail: eleni.bisognin@gmail.com 
phase the artifact and the proposal as a whole were analyzed with a view to redesigning. It can be seen that the proposed activities contributed to students' reflection on Financial Education from the applications of the content in real situations of everyday life.

Keywords: Bank loan; Financial education; Sequence of activities; PBD.

\section{RESUMEN}

El estudio utiliza el enfoque de Investigación basada en el diseño (PBD) y tiene como objetivo investigar el potencial de una secuencia de actividades que explota el Esquema de capitalización compuesta para préstamos. Se aplicó en la disciplina de Matemática Financiera con alumnos de la carrera de Licenciatura en Administración de Empresas. El trabajo se estructuró según las fases del PBD propuesto por Reeves (2000), a saber: análisis del problema educativo; elaboración del artefacto pedagógico; intervención; y, evaluación y reflexión para un rediseño del proceso. En una primera fase se analizó el curso Proyecto Pedagógico de la Administración, los Lineamientos de la Ley 9.394 / 96 y también los trabajos que tratan de la enseñanza de la Matemática Financiera; en la segunda fase se elaboró el artefacto pedagógico; en la tercera fase se aplicó la secuencia y en la cuarta fase se analizó el artefacto y la propuesta en su conjunto con miras a su rediseño. Se puede observar que las actividades propuestas contribuyeron a la reflexión de los estudiantes sobre Educación Financiera a partir de las aplicaciones de los contenidos en situaciones reales de la vida cotidiana.

Palabras clave: Préstamo bancario; Educación financiera; Secuencia de actividades; PBD.

\section{INTRODUÇÃO}

A Matemática Financeira é uma disciplina que contempla conteúdos como porcentagem e juros que são abordados desde o ensino Fundamental até o ensino Superior. Quando essa disciplina é trabalhada no ensino superior, como o Bacharelado em Administração, tem como objetivo integrar a teoria e a prática, contribuindo na formação dos futuros administradores, para que estes consigam aplicar os conceitos estudados em situações reais.

Neste sentido, buscando contribuir na construção do conhecimento dos discentes de forma satisfatória, propôs-se uma sequência de atividades sobre o Regime Capitalização Composta para Empréstimos utilizando como suporte teórico metodológico a PBD. Esta tem seu foco na interação e colaboração entre docentes/pesquisadores e estudantes envolvidos na prática pedagógica. Além disso, ela está intimamente relacionada ao desenvolvimento de um produto/artefato pedagógico.

O intuito do desenvolvimento do estudo utilizando a PBD era auxiliar na compreensão do conceito de Empréstimo Bancário, considerando que este é um conteúdo que muitas vezes os estudantes possuem dificuldade de compreensão. Dessa forma, utilizamos a PBD "[...] com o objetivo tanto de promover a melhoria das práticas educativas quanto de produzir conhecimentos sobre processo ensino-aprendizagem" (RAMOS, 2010, p. 19-20).

Nessa perspectiva, foram abordadas situações reais de empréstimos bancários analisando a viabilidade ou não, de adquirir tais produtos ofertados pelas instituições financeiras.

\section{REFERENCIAL TEÓRICO}

Nessa seção, serão apresentadas algumas reflexões sobre a PBD e expostas algumas ideias sobre Matemática Financeira e Educação Financeira. 


\subsection{Pesquisa Baseada em Design}

Introduzida por Brown (1992), a PBD vem se destacando no campo das pesquisas em Educação Matemática. Para Wang e Hannafin (2005), a PBD é uma metodologia pragmática, pois integra teoria e prática; é ancorada, pois, deve ser orientada e fundamentada com "atores" reais resolvendo problemas reais; interativa, iterativa e flexível na medida em que se desenvolve em ciclos entre pesquisa, desenvolvimento e produto (artefato); integradora, pela diversificação dos métodos com diferentes fases de planejamento, desenvolvimento e implementação; e, contextual, visto que os achados possibilitam fazer projeções além do estudado, servindo de base a novos projetos.

A PBD é uma metodologia importante para entender como, quando e por que as inovações educacionais funcionam ou não na prática (DBRC, 2003). Nesse sentido, o trabalho com a PBD propicia a sustentação do ambiente de aprendizagem através das relações teoria educacional, artefato projetado e prática. Segundo Kelly (2004), a PBD está necessariamente vinculada à produção de um artefato. Não especificamente material, mas, intervencionista como reivindicação teórica relacionada ao ensinar e aprender (AKKER, 1999).

A PBD busca investigar as possibilidades de melhoria educacional através do planejamento, aplicação e avaliação das lições, por isso pode ser tomada como uma rotina de um professor (GRAVEMEIJER; EERDE, 2009).

Conforme Reeves (2000), as fases da PBD são: análise do problema educativo; elaboração do artefato pedagógico; intervenção; e, avaliação e reflexão para um redesign do processo. Nessa perspectiva, o trabalho foi estruturado de acordo com essas fases.

\subsection{Matemática Financeira e Educação Financeira}

A Matemática Financeira é importante para o exercício da cidadania pois esse conteúdo está presente em toda a atividade humana no que se refere a trabalho, consumo e finanças (LEME, 2007).

Vieira (2010) ressalta que o ensino da Matemática Financeira aliado à educação para o consumo é desafiador, sendo que o ensino desta temática poderá ajudar as pessoas na tomada de decisão. $\mathrm{A}$ Educação Financeira, conforme Silva e Rutgers (2013, P. 12-13)

[...] constitui-se de um conjunto de informações através do qual os estudantes são introduzidos no universo do dinheiro e estimulados a produzir uma compreensão sobre finanças e economia, através de um processo de ensino, que os torne aptos a analisar, fazer julgamentos fundamentados, tomar decisões e ter posições críticas sobre questões financeiras que envolvam sua vida pessoal, familiar e da sociedade em que vivem.

Com o intuito de se aprofundar na relação ensino e aprendizagem da Matemática Financeira foi que Leme (2007), utilizou a metodologia da PBD, com enfoque na aprendizagem dos estudantes em diferentes contextos. Elaborou um experimento de ensino envolvendo os estudantes na construção de suas próprias fórmulas. $E$, usando planilhas eletrônicas efetuou cálculos de juros simples e compostos. Trabalhou em fases de experimentação, com grupo de estudantes iniciantes na Matemática Financeira e grupo de estudantes que já detinham o conhecimento sem construção de suas próprias fórmulas. Nesse contexto, a associação da metodologia PBD e a Matemática Financeira favoreceu o envolvimento dos aprendizes indicando a apropriação dos conceitos pelos mesmos. 
Para Steffe e Thompson (2000), experimentos de ensino dão ao pesquisador a oportunidade de investigar o raciocínio matemático dos estudantes a partir de experimentações que podem vir a influenciar no significado e na construção do conhecimento matemático.

Nesse sentido, Rosetti Júnior e Schimiguel (2009), ressaltam que o ensino e uso dos modelos matemáticos/financeiros devem-se dar de acordo com as necessidades dos estudantes. E destacam que, desconhecedores das possibilidades da Matemática Financeira, normalmente optam por produtos financeiros que vem comprometer a saúde financeira de suas famílias futuramente. Dessa forma, ressalta-se o importante papel da Matemática Financeira para promover a Educação Financeira e ajudar as pessoas a gerenciar suas finanças.

\section{METODOLOGIA}

Esta pesquisa foi proposta em uma disciplina de doutorado do Programa de Pós-graduação em Ensino de Ciências e Matemática PPGECIMAT - UFN e, para seu desenvolvimento, utilizou-se a metodologia da PBD. De acordo com Reeves (2000), essa metodologia compreende quatro fases. A primeira delas diz respeito à análise do problema educativo; a segunda refere-se à elaboração de um artefato ou produto educacional; a terceira diz respeito à intervenção em contextos reais de aprendizagem e, a quarta fase, refere-se a análise retrospectiva com vistas a um redesign de todo processo.

Neste trabalho a primeira fase constituiu-se da análise, pelo grupo de pesquisadoras, do Projeto Pedagógico do Curso de Administração e também das Diretrizes da lei 9.394/96. Essa análise tinha por intuito verificar se ambos estavam em consonância e para identificar os conhecimentos e habilidades necessárias aos futuros administradores apontados na literatura. Ressalta-se que a escolha de um conteúdo de Matemática Financeira se dá por esta ser uma disciplina relevante na formação dos futuros administradores e também fundamental para sua vida pessoal. Além disso, a Matemática Financeira pode ser utilizada como ferramenta da Educação Financeira que é um tema importante na vida do ser humano, para que este consiga realizar um gerenciamento adequado de suas finanças.

Na segunda fase foi elaborado um artefato pedagógico que nesse estudo foi uma sequência de atividades; a terceira fase foi a intervenção, na qual, a sequência de atividades foi aplicada pela professora regente da turma com a participação do grupo de pesquisa. Essa intervenção deu-se na disciplina de Matemática Financeira, com 21 estudantes na turma do $2^{\circ}$ semestre do Curso de Administração de uma instituição pública do interior do estado do Rio Grande do Sul. Para o desenvolvimento da aplicação foram necessários 4 períodos de de aula de 50 minutos cada.

A intervenção, conduzida pela professora regente da turma, e integrante do grupo de discentes do PPGECIMAT, foi observada por duas doutorandas professoras de Matemática que fizeram os registros escritos por meio de anotações. Além disso, foram realizadas gravações de áudio, para contribuir com a análise a posteriori e redesign do artefato.

No decorrer das atividades foram feitos questionamentos, que levavam a todo momento os estudantes a repensar e, a utilizar os conhecimentos que dispunham, de modo a contribuir para a construção de novos conhecimentos a partir da interpretação e análise de cada uma das situações reais. 
Foram analisados, na quarta fase, o artefato desenvolvido e a intervenção proposta, vislumbrando o redesign. Ressalta-se que o tempo destinado para cada fase na PBD varia de acordo com o contexto e o público-alvo.

\section{ANÁLISE DO PROBLEMA EDUCATIVO}

A Educação Financeira é uma temática relevante na formação dos futuros administradores. Fundamental para sua vida pessoal, e do ser humano como um todo para que este seja capaz de "[...] analisar, fazer julgamentos fundamentados, tomar decisões e ter posições críticas sobre questões financeiras que envolvam sua vida pessoal, familiar e da sociedade em que vivem" (SILVA; RUTGERS, 2013, p. 12-13).

Iniciamos nossa pesquisa analisando o Projeto Pedagógico do curso de Bacharelado em Administração; as diretrizes do curso superior em Administração e trabalhos existentes na literatura que abordam a importância do estudo dos conceitos de Matemática Financeira.

O curso superior de Bacharelado em Administração tem como objetivo geral formar profissionais com sólida formação teórica e prática, visando a sustentabilidade das organizações a partir do desenvolvimento de habilidades e competências de gestão e liderança. Os objetivos específicos destacados para este curso são: dar significado e aprofundamento ao conhecimento acadêmico; preparar cidadãos e profissionais aptos para a intervenção na realidade; priorizar a ética e o desenvolvimento da autonomia e do pensamento em qualquer nível organizacional; formar profissionais capazes de buscar soluções para os problemas de diversas áreas das organizações e com visão crítica e humanística.

A matriz curricular do curso é dividida em oito semestres, sendo que a disciplina de Matemática Financeira está prevista para ser ofertada no segundo semestre. O currículo do curso valoriza a formação acadêmica articulada ao mundo do trabalho, viabilizando a articulação entre os conhecimentos construídos nas diferentes disciplinas do curso com a prática real de trabalho.

O PPC do curso de Bacharelado em Administração está em consonância com as diretrizes na Lei 9.394/96, Art. 43, inciso II e III, no que compromete-se em preparar profissionais aptos para a sua inserção no campo do desenvolvimento social, resultando num profissional adaptável a mudanças.

No que tange às competências e habilidades, a lei ainda discorre que o futuro profissional administrador deve pelo menos: reconhecer e definir problemas, equacionar soluções, pensar estrategicamente; desenvolver raciocínio lógico, crítico e analítico; ter iniciativa, criatividade, determinação, vontade política e administrativa, vontade de aprender, ser aberto às mudanças; ser capaz de transferir conhecimentos da vida e da experiência cotidianas para o ambiente de trabalho e do seu campo de atuação profissional.

Nesse sentido, as atividades propostas aos estudantes vêm a corroborar para a formação do futuro administrador. Pretende-se com a estratégia adotada para o desenvolvimento dessas atividades, promover mais do que a apropriação de conceitos do Regime de Capitalização Composta, mas também, propiciar um olhar desse futuro profissional sobre transações financeiras tanto coletivas como individuais aprimorando, desse modo, sua Educação Financeira, tão em voga e importante atualmente. 
De acordo com Leme (2007) a Matemática Financeira busca evidenciar a vivência do estudante como instrumento de mudanças e como ferramenta para o exercício da cidadania. Considerando essa concepção, este trabalho busca consolidar este propósito, pois a atividade aqui descrita teve um caráter exploratório, instigando os estudantes a trabalhar suas receitas de forma consciente. Assim, como também destacam Rosetti Júnior e Schimiguel (2009), muitos por desconhecimento ou por dificuldade de aprender Matemática Financeira acabam por prejudicar a saúde financeira familiar. Ainda explicitam que, os cálculos financeiros são ferramentas fundamentais na tomada de decisão e na gestão financeira de empresas, comunidades, famílias e pessoas.

Hermínio (2008) destaca a importância da aprendizagem de conceitos de Matemática Financeira pois ajuda os estudantes a entender melhor as relações comerciais e a serem mais críticos na exigência dos seus direitos. Ainda, segundo o mesmo autor, uma possibilidade a ser adotada no ensino da Matemática Financeira é trazer situações do mundo real para serem analisadas na sala de aula para que os estudantes visualizem situações reais de aplicação do conteúdo. Ainda segundo esse autor "[...] seria importante contar com a possibilidade de os alunos serem ouvidos sobre suas análises e conclusões para cada tipo de decisão tomada no contexto do problema resolvido ou que se quer resolver." (HERMÍNIO, 2008, p. 55).

Nessa perspectiva, neste trabalho, os conceitos de Matemática Financeira são explorados a partir de dados coletados pelos estudantes a partir de situações reais. Os estudantes podem analisar os dados e expor suas considerações e conclusões sobre a viabilidade de realizar o empréstimo bancário.

\section{CONSTRUÇÃO DO ARTEFATO PEDAGÓGICO}

O artefato utilizado neste trabalho consiste em uma sequência didática de atividades envolvendo conceitos referentes ao Regime de Capitalização Composta, tópico este que faz parte da ementa da disciplina de Matemática Financeira.

Inicialmente, os estudantes foram divididos em grupos e cada grupo ficou responsável em realizar uma pesquisa, junto a uma instituição financeira, em relação às condições oferecidas pela mesma para realização de um empréstimo bancário. Os estudantes buscaram dados relativos ao valor de empréstimo que conseguiriam tomar, como também o prazo para pagamento desse capital, tendo por base o salário médio calculado entre os integrantes do grupo.

$\mathrm{Na}$ aula foi realizada a análise dos dados coletados pelos estudantes. Essa atividade de análise foi organizada em três etapas como pode ser observado no Quadro 1.

Quadro 1 - Síntese da atividade desenvolvida

\begin{tabular}{|c|l|}
\hline \multicolumn{1}{|c|}{ Etapa } & \multicolumn{1}{c|}{ Questionamento/o que deve ser realizado } \\
\hline 1: questionamentos... & $\begin{array}{l}\text { - Que renda média o grupo definirá como salário? } \\
\text { - Faça uma simulação variando o tempo para pagamento integral do empréstimo. }\end{array}$ \\
\hline 2: análise de dados & $\begin{array}{l}\text { - Faça uma análise da simulação com os dados bancários pesquisados para verificar a } \\
\text { viabilidade da efetivação do empréstimo no banco escolhido. Destaque as facilidades } \\
\text { oferecidas pelo banco, bem como, as dificuldades encontradas (na visão do grupo). } \\
\text { - Orientação: entregar um texto, destacar as tabelas construídas na planilha eletrônica. }\end{array}$ \\
\hline
\end{tabular}




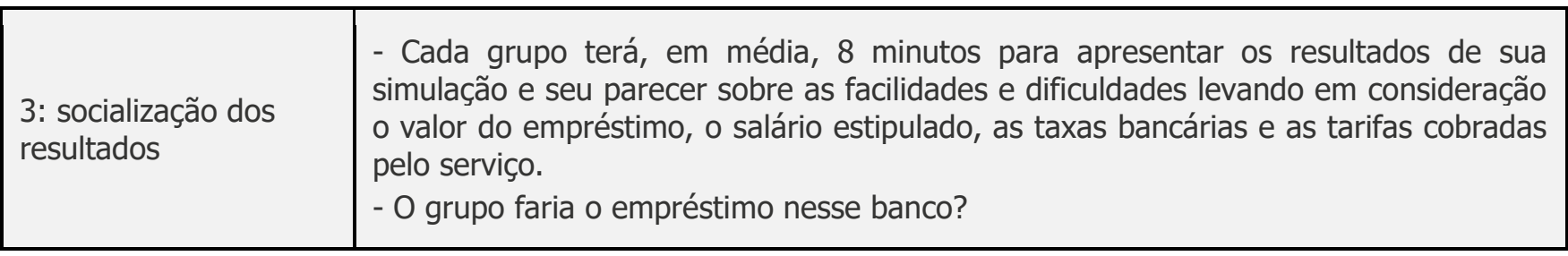

Fonte: construído pelas autoras.

Os estudantes analisaram as condições que o banco oferece quanto ao valor do empréstimo, tempo necessário para o pagamento, à taxa de juros e tarifas bancárias; também fizeram simulações em planilhas eletrônicas variando o tempo para pagamento integral do valor tomado na instituição financeira, buscando com isso verificar a viabilidade da efetivação do empréstimo no banco escolhido. Em seguida, os estudantes elaboraram um texto expondo os resultados de sua análise, as facilidades oferecidas pelo banco pesquisado e as dificuldades encontradas na visão do grupo. Para finalizar foi realizado, um momento de socialização dos resultados, em que cada grupo apresentou sua análise e conclusões; a partir desses resultados, propôs-se uma discussão crítica no grande grupo com relação à tomada de empréstimos. Foram avaliados, nessa discussão, os pontos positivos e negativos das situações relatadas, possibilitando-se abordar aspectos da Educação Financeira, como consequências do mau uso do dinheiro.

\section{AVALIAÇÃO DA INTERVENÇÃO PELO GRUPO DE ESTUDANTES}

A avaliação da intervenção foi realizada por meio da análise das tabelas construídas pelos grupos, juntamente com a síntese elaborada por eles baseada nas informações fornecidas pelas instituições financeiras e, das respostas dadas pelos estudantes a um questionário aplicado após a realização das atividades da sequência didática.

Na sequência apresenta-se a análise de algumas planilhas construídas pelos grupos juntamente com a síntese elaborada. Os dados utilizados para construção da planilha foram obtidos pelos estudantes junto às instituições financeiras da cidade. A Tabela 1, apresenta a simulação construída pelo grupo $A$ a partir dos dados obtidos junto à instituição financeira $X$.

Tabela 1 - Simulação de empréstimo da instituição financeira X

\begin{tabular}{|c|c|c|c|c|c|c|}
\hline $\begin{array}{c}\text { Valor do } \\
\text { Financiamento }\end{array}$ & $\begin{array}{c}\text { Taxa Nominal } \\
\text { (a.m.) }\end{array}$ & \multicolumn{2}{|c|}{ Condições } & IOF & Parcela & Renda \\
\hline$R \$ 5680,00$ & 4,62 & & $24 x$ & 3,38 & $\mathrm{R} \$ 396,55$ & $\mathrm{R} \$ 1342$ \\
\hline $\begin{array}{c}\text { Valor do } \\
\text { empréstimo }\end{array}$ & \multicolumn{2}{|c|}{$\begin{array}{c}\text { Tempo Pagamento } \\
\text { (meses) }\end{array}$} & \multicolumn{2}{|c|}{ Taxa Juros } & Montante & Juros \\
\hline$R \$ 5680$ & \multicolumn{2}{|l|}{6} & \multicolumn{2}{|c|}{$4,62 \%$} & $\mathrm{R} \$ 7.447,95$ & $\mathrm{R} \$ 1.767,95$ \\
\hline $\mathrm{R} \$ 5680$ & \multicolumn{2}{|l|}{12} & \multicolumn{2}{|c|}{$4,62 \%$} & $R \$ 9.766,18$ & $\mathrm{R} \$ 4.086,18$ \\
\hline$R \$ 5680$ & \multicolumn{2}{|l|}{18} & \multicolumn{2}{|c|}{$4,62 \%$} & $\mathrm{R} \$ 12.805,99$ & $\mathrm{R} \$ 7.125,99$ \\
\hline$R \$ 5680$ & \multicolumn{2}{|l|}{24} & \multicolumn{2}{|c|}{$4,62 \%$} & $\mathrm{R} \$ 16.791,96$ & $\mathrm{R} \$ 11.111,96$ \\
\hline$R \$ 5680$ & \multicolumn{2}{|l|}{30} & \multicolumn{2}{|c|}{$4,62 \%$} & $\mathrm{R} \$ 22.018,61$ & $R \$ 16.338,61$ \\
\hline
\end{tabular}

Fonte: dados da pesquisa. 
No Quadro 2 é apresentada a síntese elaborada pelo grupo A, na qual eles fazem a análise da viabilidade de adquirir o empréstimo, as facilidades e dificuldades encontradas.

Quadro 2 - Síntese elaborada pelo grupo A a partir da análise da simulação do empréstimo

Através da tentativa de empréstimo, podemos analisar que houve certa dificuldade em obter os dados necessários por parte da instituição A, os mesmos não estavam claros para serem analisados.

$O$ valor conseguido para financiar foi de $\mathbf{R} \$ 5.680,00$, com taxa efetiva de 4,62\% a.m, em 24x a forma de pagamento, onde o valor da parcela é $\mathbf{R} \$ 396,55$, em que não pode ultrapassar os $30 \%$ da renda, ( $R \$ 1.342,00)$.

Dessa forma, observamos que não é viável a tomada desse crédito, devido ao montante ser um valor expressivo, dando mais que o dobro do capital inicial, $\mathbf{R} \$ 11.111,96$.

\section{As dificuldades:}

- sem acesso a simulação na internet;

- falta de interesse da financiadora para disponibilizar os dados.

Fonte: dados da pesquisa.

O Grupo B coletou informações baseadas em uma renda mensal de um salário-mínimo, sendo a simulação criada por eles apresentada na Tabela 2.

Tabela 2 - Simulação de empréstimo da instituição financeira Y

\begin{tabular}{c|c|c|c|c}
\hline Capital & Taxa (a.m) & Tempo (meses) & Montante & Juro \\
\hline $\mathrm{R} \$ 9.500,00$ & $2,63 \%$ & 6 & $\mathrm{R} \$ 11.101,19$ & $\mathrm{R} \$ 1.601,19$ \\
\hline $\mathrm{R} \$ 9.500,00$ & $2,63 \%$ & 12 & $\mathrm{R} \$ 12.972,26$ & $\mathrm{R} \$ 3.472,26$ \\
\hline $\mathrm{R} \$ 9.500,00$ & $2,63 \%$ & 18 & $\mathrm{R} \$ 15.158,68$ & $\mathrm{R} \$ 5.658,68$ \\
\hline $\mathrm{R} \$ 9.500,00$ & $2,63 \%$ & 24 & $\mathrm{R} \$ 17.713,63$ & $\mathrm{R} \$ 8.213,63$ \\
\hline $\mathrm{R} \$ 9.500,00$ & $2,63 \%$ & 30 & $\mathrm{R} \$ 20.699,20$ & $\mathrm{R} \$ 11.199,20$ \\
\hline
\end{tabular}

Fonte: dados da pesquisa.

O Quadro 3 apresenta os pontos positivos e negativos da simulação referente a instituição $Y$ destacados pelo grupo $B$.

Quadro 3 - Síntese elaborada pelo grupo B a partir da análise da simulação do empréstimo

A instituição financeira $Y$ oferece empréstimo a partir de uma renda mínima no valor de $\mathbf{R} \$ \mathbf{9 9 8 , 0 0}$ e a parcela compromete 30\% da renda e com isso é possível parcelar no máximo até 72 meses com um capital máximo de $\mathbf{R} \$ 9.500,00$. As taxas variam entre 2,63\% que é a taxa efetiva e 2,5\% que é taxa nominal. Um dos pontos negativos é que quanto menor for a renda e maior o número de parcelas, maiores serão as taxas aplicadas, sendo assim, o valor final a ser pago será 6 vezes maior que o capital inicial, e também é prometido que a taxa aplicada será a nominal com o valor de 2,5\%, sendo que no decorrer das parcelas será a taxa efetiva que será aplicada ao valor do pagamento aumentando assim as parcelas. $E$ o ponto positivo é que quanto maior for a renda melhor será a forma de pagamento, pois o tempo de pagamento será reduzido e as taxas serão menores e o banco possui uma taxa abaixo da média do mercado. 
Após a realização das atividades da sequência, os estudantes responderam um questionário individual, visando contribuir para o redesign do artefato.

Em linhas gerais, as respostas dos estudantes foram positivas, apontando que a sequência de atividades desenvolvidas contribuiu para o despertar de um olhar crítico em relação à Educação Financeira, por meio da análise das condições oferecidas pelos bancos.

A primeira pergunta do questionário buscava verificar se a atividade desenvolvida contribuiu na compreensão dos passos necessários para a tomada de decisão sobre um empréstimo bancário. Todos os estudantes responderam que sim, ressaltando que com as atividades foi possível fazer uma análise das condições oferecidas pelas instituições financeiras, observando os juros, o tempo, o montante, o percentual que compromete do salário, a fim de identificar as condições mais adequadas de acordo com as necessidades. Pode-se observar, no Quadro 4, as respostas dos estudantes.

Quadro 4 - Respostas dos estudantes E1, E3 e E7 para a primeira questão do questionário que avaliou o artefato pedagógico

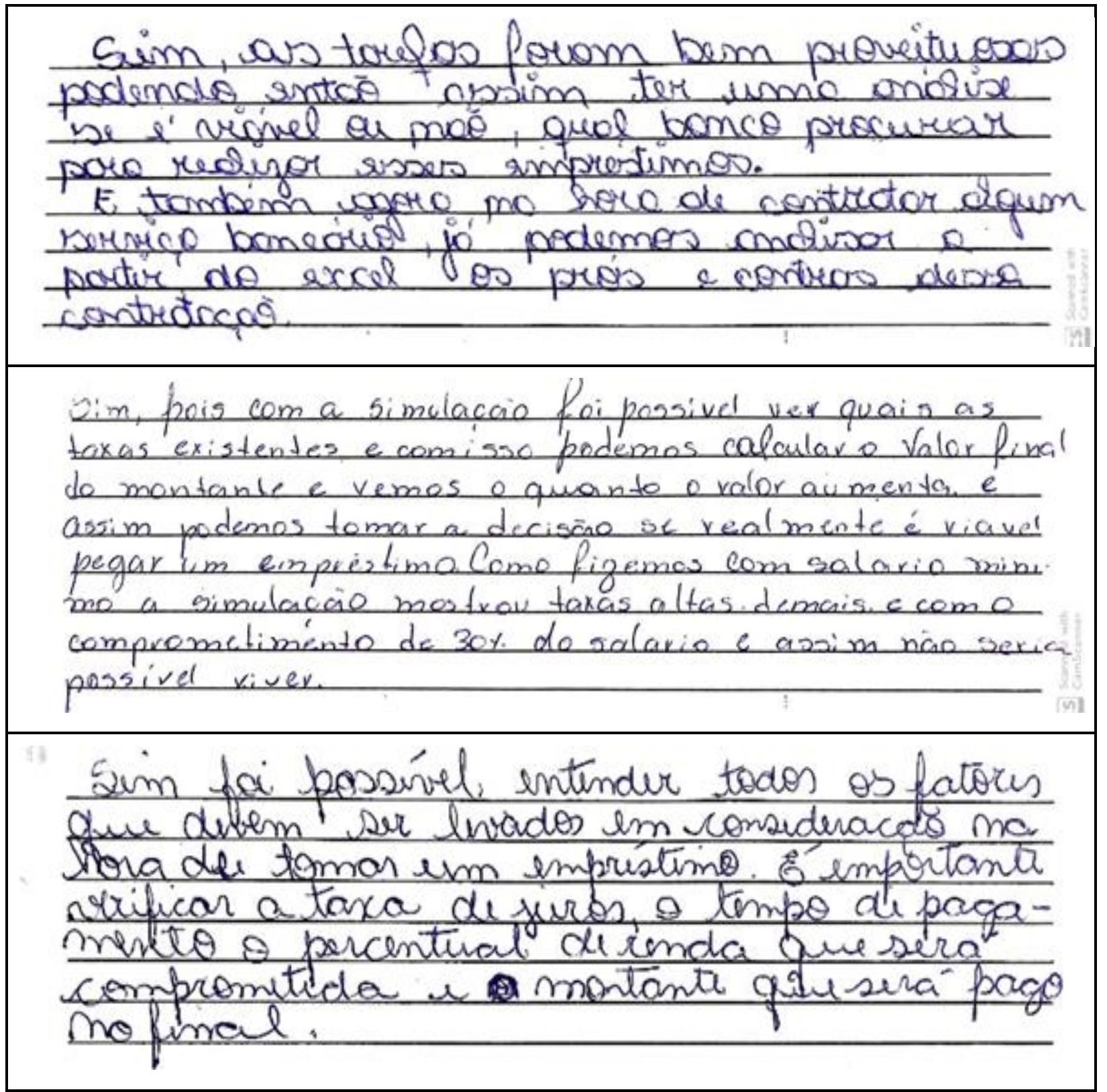

Fonte: dados da pesquisa. 
Na segunda questão os estudantes deveriam argumentar sobre os aspectos relevantes para a tomada de decisão no empréstimo bancário. Apontaram que se deveria considerar a taxa de juros, a real necessidade de fazer o empréstimo, o tempo e a renda comprometida para pagamento da parcela, como pode ser observado nas respostas apresentadas no Quadro 5.

Quadro 5 - Respostas dos estudantes E2, E8 e E11 para a segunda questão do questionário que avaliou o artefato pedagógico

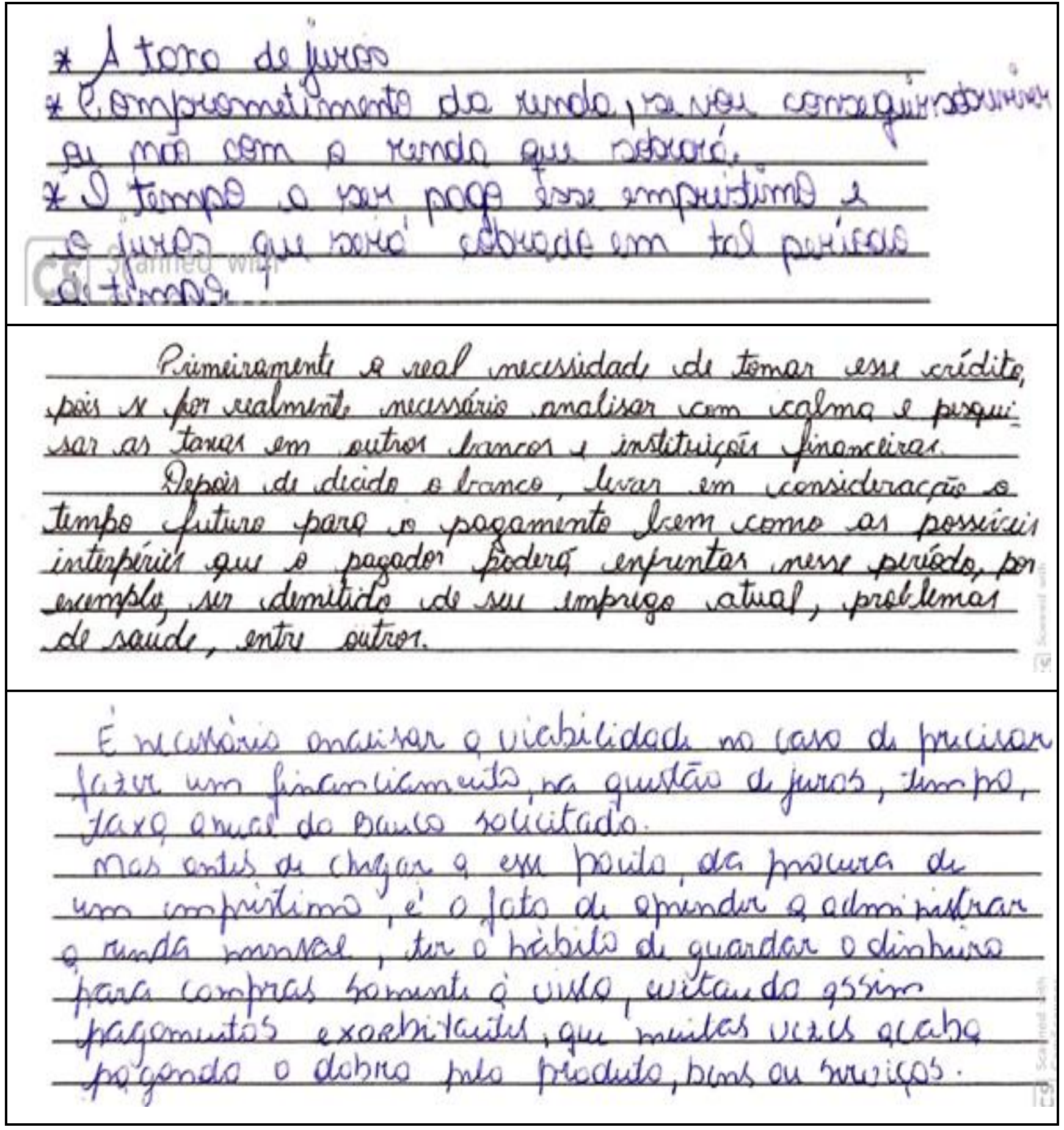

Fonte: dados da pesquisa.

A última questão, tratava da estratégia de ensino proposta na aula. A maioria (20) ressaltou a importância da aplicação do conteúdo em situações reais, exigindo análise e tomada de decisão de acordo com as condições do empréstimo oferecidas pelas instituições financeiras pesquisadas, apresenta-se no Quadro 6 algumas destas respostas. 
Quadro 6 - Respostas dos estudantes E11, E2 e E6 para a terceira questão do questionário que avaliou o artefato pedagógico

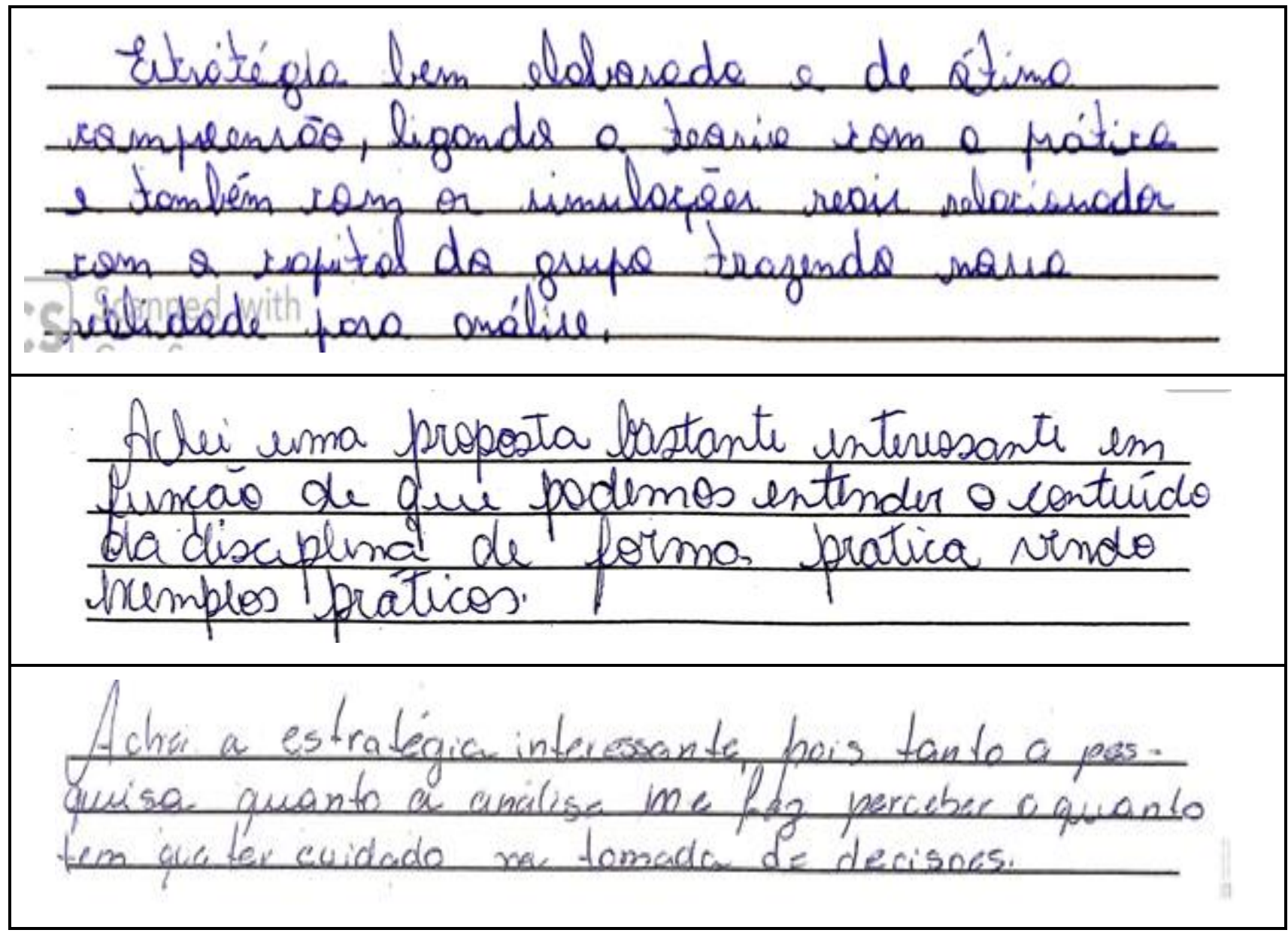

Fonte: dados da pesquisa.

Analisando as respostas, nota-se que houve uma avaliação positiva das atividades propostas. Contribuindo de forma crítica e reflexiva na formação de futuros administradores.

\section{ANÁLISE E AVALIAÇÃO DA INTERVENÇÃO: O REDESIGN}

Finalizando o primeiro ciclo da PBD com as avaliações dos estudantes, do professor da disciplina e dos observadores, pensou-se o redesign. Após a análise podemos destacar alguns aspectos a serem revistos em futuras aplicações. O primeiro aspecto refere-se à organização dos grupos, pois os estudantes relataram que apresentaram dificuldade em conseguir os dados nas instituições financeiras por não serem correntistas. Assim, uma alternativa para superar essa dificuldade é organizar os grupos de forma que pelo menos um dos estudantes tenha conta no banco em que irá buscar os dados.

Outro, refere-se aos cálculos realizados pelos estudantes usando as fórmulas da planilha eletrônica. Um grupo errou a fórmula do juro (trocaram a taxa e o tempo), obtendo valor da parcela e juros incorretos. A solução seria solicitar que os estudantes confiram os cálculos da planilha eletrônica na calculadora HP-12C.

Outro aspecto relatado pelos estudantes está relacionado aos dados fornecidos pelas instituições financeiras. Os valores encontrados em seus cálculos não coincidiam com os fornecidos pelas instituições financeiras. A alternativa, neste caso, é, após a análise dos dados coletados, convidar um 
especialista no assunto para um debate no qual possam sanar dúvidas e compreender melhor as variáveis envolvidas nas transações financeiras.

Percebeu-se ainda que grande parte dos estudantes não compreenderam a terceira pergunta do questionário, dadas as respostas apresentadas. Sendo necessário sua reelaboração.

\section{CONSIDERAÇÕES FINAIS}

Entende-se que o objetivo de investigar as potencialidades de uma sequência didática que utiliza a abordagem da PBD e explora o Regime de Capitalização Composta para Empréstimos, tópico da disciplina de Matemática Financeira, com estudantes de um curso de Bacharelado em Administração foi alcançado.

A atividade proposta contribuiu para estimular os estudantes a refletirem sobre Educação Financeira, para a formação de sujeitos críticos e para tomada de decisões. Evidenciou ainda, os problemas que a falta de organização financeira e de reserva de emergência podem acarretar.

Além disso, a atividade possibilitou aos estudantes serem mais autônomos, visto que os próprios realizaram as simulações, tiraram conclusões e produziram conhecimento a partir da experiência vivenciada.

Ressalta-se que a metodologia da PBD foi importante, pois contribuiu para a reflexão do grupo de doutorandas, desde a etapa da escolha do conteúdo, planejamento das atividades e, também, na avaliação da intervenção, e identificação dos aspectos a serem melhorados no redesign. Dessa forma, a PBD foi essencial, e, suas fases importantes para o êxito do trabalho, evidenciando as adaptações necessárias à sequência de atividades.

Conclui-se assim, que a proposta agrega na formação dos futuros administradores, possibilidades de verificar aplicações do conteúdo em situações da vida cotidiana, como também na formação do grupo de doutorandas, possibilitando repensar o planejamento e a prática docente, desenvolvidas em cursos técnicos e/ou tecnológicos com enfoque na Matemática, numa situação que articula ensino e pesquisa.

\section{REFERÊNCIAS}

AKKER, Jan van den. Principles and Methods of Development Research. In: AKKER, Jan van den; BRANCH, Robert Maribe; GUSTAFSON, Kent; NIEVEEN, Nienke; PLOMP, Tjeerd. Design Approaches and Tools in Education and Training. Netherlands: Kluwer Academic Publishers, p. 1-14, 1999.

BRASIL. LEI No 9.394, de 20 de Dezembro de 1996. Estabelece as diretrizes e bases da educação nacional. Disponível em: http://www.planalto.gov.br/ccivil_03/leis/l9394.htm. Acesso em 02 set. 2019.

BROWN, Ann Lesley. Design experiments: theoretical and methodological challenges in creating complex interventions in classroom settings. The Journal of the Learning Sciences, Madison, v.2, n.2, p.141-178, 1992.

DESIGN-BASED RESEARCH COLLECTIVE (DBRC). Design-based research: an emerging paradigm for educational inquiry. Educational Researcher, v. 32, n. 1, p. 5-8, 2003. 
GRAVEMEIJER, Koeno; EERDE, Dolly van. Design research as a means for building a knowledge base for teachers and teaching in mathematics education. The Elementary School Journal, v. 109, n.5, p. 510-524, 2009.

HERMINIO, Paulo Henrique. Matemática Financeira - um enfoque da Resolução de Problemas como Metodologia de Ensino e Aprendizagem. 2008. 244f. Dissertação (Programa de PósGraduação em Educação Matemática) - Universidade Estadual Paulista, Rio Claro, 2008.

KELLY, Anthony. Design research in education: yes, but is it methodological? The Journal of the Learning Science, v.13, n.1, p.115-128, 2004.

LEME, Nelson Dias. 0 ensino-aprendizagem de Matemática Financeira utilizando ferramentas computacionais: uma abordagem construcionista. 2007. 198 f. Dissertação (Mestrado em Educação Matemática) - Pontifícia Universidade Católica de São Paulo, São Paulo, 2007.

PROJETO PEDAGÓGICO DO CURSO SUPERIOR DE BACHARELADO EM ADMINISTRAÇÃO.

Campus Júlio de Castilhos. Disponível em: https://www.iffarroupilha.edu.br/projetopedag\%C3\%B3gico-de-curso/campus-j\%C3\%BAlio-de-castilhos. Acesso em: 8 set. 2019.

ROSETTI JÚNIOR, Hélio; SCHIMIGUEL, Juliano. Educação Matemática Financeira: conhecimentos financeiros para a cidadania e inclusão. Revista Científica Internacional: Inter Science Place, ano 2, n. 9, p. 113, out/nov., 2009.

RAMOS, Paula. Ambiente Virtual Vivências: análise do processo de desenvolvimento na perspectiva da pesquisa baseada em design. Rio de Janeiro: UFRJ/ NUTES, 2010. 240 f. Tese (Doutorado) - Programa de Pós-Graduação em Educação em Ciências e Saúde, Núcleo de Tecnologia Educacional para a Saúde, Universidade Federal do Rio de Janeiro, Rio de Janeiro, 2010.

REEVES, Thomas C. Enhancing the worth of instructional technology research trough "Design Experiments" and other developmental research strategies. In: Annual meeting of the American Educational Research Association (AERA), 10, 2000, New Orleans, LA. Anais... New Orleans, LA: American Educational Research Association, 2000. p. 1-15.

SILVA, Amarildo Melchiades da; RUTGERS, Arthur Belford Powell. Um programa de Educação Financeira para a Matemática escolar da Educação Básica. In: ENEM, XI, 2013, Curitiba. Anais... Curitiba: 2013, p. 1-17.

STEFFE, Lesly P.; THOMPSON, Patrick. W. Teaching Experiment Methodology: Underlying Principles and Essential Elements. In: LESH, Richard; KELLY, Anthony E. (Ed.). Research design in mathematics and science education. Hillsdale, NJ: Erlbaum, 2000, p. 267-307.

VIEIRA, Leandro Carvalho. A Matemática Financeira no ensino médio e sua articulação com a cidadania. 2010. 91f. Dissertação (Mestrado Profissional em Educação Matemática) Universidade Severino Sombra, Vassouras, 2010.

WANG, Feng.; HANNAFIN, Michael J. Design-based research and technology-enhanced learning environments. ETR\&D, v. 53, n. 4, p. 5-23, 2005.

Submissão: 18/03/2021

Aceito: 31/03/2021 